\title{
Successful Conservative Management of Primary Hyperparathyroidism Diagnosed During Pregnancy
}

\author{
Orkun Cetin $^{1 *}$, Murat Atmaca ${ }^{2}$, Zehra Kurdoglu ${ }^{3}$, Numan Cim ${ }^{1}$, Recep Yıldızhan ${ }^{1}$, Hanım Guler Sahin ${ }^{1}$, \\ Mertihan Kurdoglu ${ }^{4}$
}

\begin{abstract}
Introduction: Primary hyperparathyroidism (PHP) a rare condition that leads to severe maternal and fetal complications in pregnancy. In this report, we aimed to present the successful conservative medical treatment of PHP diagnosed during pregnancy. Case Presentation: A 32-year-old pregnant woman was referred to our clinic at 14 weeks of gestation with severe vomiting, chronic constipation and proximal muscle weakness. According to the clinical presentation, PHP was diagnosed on the basis of biochemical and ultrasonographic findings. The patient was treated with high fluid intake, low calcium diet, oral phosphate supplementation and intramuscular injection of calcitonin. At 38 weeks of gestation, healthy infant was delivered by cesarean section with mild preeclampsia.

Conclusion: Treatment options of PHP, including medical and surgical therapy are debated in the literature. Early diagnosis and effective management may reduce perinatal mortality and morbidity. Although surgical treatment in the second trimester is the definitive therapy, conservative management can be preferred in mild cases of PHP in pregnancy.

Keywords: Disease management, Pregnancy, Primary hyperparathyroidism
\end{abstract}

\section{Introduction}

Primary hyperparathyroidism (PHP) is the third most common endocrine disorder after diabetes and thyroid disease. Women are affected twice as common as men (1). Although PHP is a very rare condition during pregnancy, it may cause feto-maternal morbidity and mortality (2). The prevalence of hyperparathyroidism in pregnancy varies from $0.15 \%$ to $1.4 \%$ (3). PHP occurs due to decreased negative feedback control and autonomous parathyroid hormone production by the parathyroid glands. The most frequent reason of PHP is a single parathyroid adenoma (85\%) followed by parathyroid hyperplasia (15\%-20\%) (4).

The treatment of PHP during pregnancy is based on severity of the disease. The optimal management in pregnancy has been debated in the literature. Conservative therapy for hypercalcemia may induce preterm delivery (5). Surgery is the most definitive treatment of PHP. Although it reduce the incidence of life-threatening maternal and fetal complications such as pre-eclampsia, miscarriage and hypercalcemic crisis, may provoke spontaneous abortion and preterm delivery (6). In this report, we aimed to present the successful conservative medical treatment of PHP diagnosed at 14 weeks of pregnancy.

\section{Case Presentation}

A 32-year-old pregnant woman was referred to Yuzuncu Yll University Medical School, Obstetrics and Gynecology, Department of Perinatology, Van, Turkey at 14 weeks of gestation with severe vomiting, chronic constipation and proximal muscle weakness. There was a history of intrauterine fetal demise at third trimester in previous pregnancy. Detailed obstetric ultrasound examination was normal. According to the clinical presentation, hyperemesis gravidarum was considered as differential diagnosis. Initial laboratory findings revealed calcium level of 11.7 $\mathrm{mg} / \mathrm{dl}$ (reference range 8.4-10.4 mg/dl), phosphate level of $1.8 \mathrm{mg} / \mathrm{dl}$ (reference range $2.3-4.0 \mathrm{mg} / \mathrm{dl}$ ), alkaline phosphatase level of 187 (reference range 30-120 U/L), urine calcium level of $315 \mathrm{mg} /$ day (reference range 100-250 mg/ day) and also parathyroid hormone (PTH) level of $89 \mathrm{pg} /$ $\mathrm{ml}$ (reference range 16-48 $\mathrm{pg} / \mathrm{ml}$ ). Serum thyrotropine, free thyroxine and free triiodothyronine levels were normally. A solid, hypoechoic nodule measured $1.8 \times 0.5 \times$ $1.1 \mathrm{~cm}$ in the left inferior parathyroid gland on ultrasonography was detected. Finally, PHP was diagnosed on the basis of biochemical findings.

Firstly, the patient was treated with high fluid intake, low calcium diet and oral phosphate ( $3 \mathrm{~g} /$ day) by monitoring 
plasma calcium and phosphate levels on weekly period, conservatively. The symptoms of proximal muscle weakness and vomiting were progressed to 20 weeks of gestation despite of conservative treatment. We recommended to patient parathyroid surgery in the second trimester, as a radical and definitive treatment of PHP. After informing the patient about benefits and risks associated with this procedure, she declined surgical therapy during pregnancy. Therefore, we started calcitonin at the dose of $4 \mathrm{mg} /$ $\mathrm{kg}$ intramuscularly, 2 times during pregnancy to treat persistent symptoms of hypercalcemia.

At 38 weeks of gestation, mild preeclampsia was developed as a complication of PHP. A 3150 g, Apgar score 7-9 healthy, male infant was delivered by cesarean section without admission to the neonatal intensive care unit. Early neonatal hypocalcemia was detected with a calcium level of $7.1 \mathrm{mg} / \mathrm{dl}$. We started intravenous calcium infusion (calcium gluconat, $400 \mathrm{mg} / \mathrm{kg} /$ day) and active vitamin D (calcitriol, $50 \mathrm{ng} / \mathrm{kg} /$ day) treatment to the newborn to increase serum calcium level. The infusion was continued for following two days of delivery. The patient and newborn were discharged on the fifth day of cesarean section. Maternal conservative treatment without calcitonin was continued in the postpartum period. Open focused parathyroidectomy was performed to the patient 6 months later.

\section{Discussion}

The prevalence of PHP during pregnancy is probably underestimated because of non-recognition and selective reporting. In a previous study, PHP varies from $0.15 \%$ to $1.4 \%$ during pregnancy (3). The most important cause of PHP is a solitary parathyroid adenoma. Maternal complications of untreated parathyroid disorder can led to nephrolithiasis, hyperemesis or potentially life-threatening complications such as hypercalcemic crisis, preeclampsia and pancreatitis (7). Intrauterine growth retardation, low birth weight, preterm delivery, intrauterine fetal demise and postpartum neonatal tetany may occuras fetal complications (8). Early diagnosis and effective management of this condition can reduce feto-maternal mortality and morbidity.

Clinical manifestations of PHP may be similar to pregnancy-related disorders. Therefore, some physiological modifications of pregnancy can mask typical symptoms of PHP. Correct diagnosis of PHP in pregnancy plays an important role due to the significant risk of pre-perinatal mortality. In our case, the patient complained about non-specific symptoms like severe vomiting and proximal muscle weakness. The other finding for PHP was the history of intrauterine fetal demise in previous pregnancy. Ultrasonographic examination is the preferred imaging modality during pregnancy for location of parathyroid adenomas with a sensitivity of $69 \%$ and a specificity of $94 \%$. Computerized tomography and sestamibi scintigraphy are contraindicated during pregnancy due to possible risks of ionizing radiation (9).

PHP during pregnancy necessitates an effective manage- ment because of the serious complications reported in untreated cases (10). Lack of evidence based guidelines often raises the dilemma between a conservative and surgical approach. Medical treatment may be an option during the first trimester of pregnancy, especially if symptoms and calcium levels can be controlled by drug therapy (3). In our case, conservative medical treatment consists of low calcium diet, high fluid intake and oral phosphate until 20 weeks of gestation. By reason of progressive hypercalcemic symptoms, we started a therapy with intramuscular injection of calcitonin. Calcitonin is considered the safest conservative treatment option due to negligible passage through the placenta in patients with hypercalcemia during pregnancy (11). Authors recommend that total plasma calcium must be lower than $3.0 \mathrm{mmol} / \mathrm{L}$ to avoid serious complications (12). Calcitonin treatment can be associated with tachyphylaxis. High doses of calcitonin during pregnancy may cause low birth weight in some animal studies $(13,14)$. These complications were not observed in our patient.

A minimally invasive parathyroidectomy in the second trimester of pregnancy is the most definitive and effective management of PHP. Parathyroidectomy is associated with a slightly increased risk of spontaneous abortion and preterm delivery (15). Surgery in the second trimester is safer than the other trimesters due to the lowest risk of anesthesia-induced preterm delivery and completion of organogenesis (16). In our case, the patient declined option of surgical treatment because of the potential complications.

Maternal PHP causes suppression of fetal parathyroid glands secondary to an increase in net calcium flux across the placenta to the fetus. Transient suppression of fetal parathyroid function may result in severe neonatal hypocalcemia that leads to seizures (17). Neonatal hypocalcemic tetany, which usually occurs during the first 72 hours, may depend on maternal PHP (18). In our case, transient neonatal hypocalcemia without neonatal tetany was detected in the first day after delivery, treated by intravenous calcium and active vitamin $\mathrm{D}$ administration.

\section{Conclusion}

PHP during pregnancy is a rare and preventable cause of feto-maternal morbidity and mortality. Early correct diagnosis is essential for the management of PHP to avoid serious complicationsduring pregnancy. Conservative management should be preferred in mild cases of PHP. Oral phosphate supplementation and intramuscular injection of calcitonin are safe and appropriate options of the treatment. On the other hand, surgical treatment in the second trimester is the gold standard and definitive therapy for PHP. Treatment options should be individualized to each pregnant woman based on the severity of the disease.

\section{Ethical issues}

Written informed consent was obtained from the patient who participated in this study.

\section{Conflict of interests}

The authors declare no conflict of interests. 


\section{Financial support}

The authors declared that this study has received no financial support.

\section{Acknowledgements}

The authors declare that there is no acknowledgement.

\section{References}

1. Kokrdova Z. Pregnancy and primary hyperparathyroidism. J Obstet Gynaecol. 2010;30(1):57-9. doi: 10.3109/01443610903315611.

2. Pieringer $H$, Hatzl-Griesenhofer $M$, Shebl $O$, Wiesinger-Eidenberger G, Maschek W, Biesenbach G. Hypocalcemic tetany in the newborn as a manifestation of unrecognized maternal primary hyperparathyroidism. Wien Klin Wochenschr. 2007;119(3-4):129-131. doi: 10.1007/s00508-0060748-1.

3. Schnatz PF, Curry SL. Primary hyperparathyroidism in pregnancy: evidence-based management. Obstet Gynecol Surv. 2002;57:365-376. doi: 10.1097/01. OGX.0000017377.65823.CA.

4. Rodgers SE, Lew JI, Solórzano CC. Primary hyperparathyroidism. Curr Opin Oncol. 2008; 20(1):52-58.

5. Kelly TR. Primary hyperparathyroidism during pregnancy. Surgery. 1991;110(6):1028-1034.

6. Norman J, Politz D, Politz L. Hyperparathyroidism during pregnancyand the effect of rising calcium on pregnancy loss: a call for earlierintervention. Clin Endocrinol (Oxf). 2009;71(1):104-109. doi: 10.1111/j.1365-2265.2008.03495.x.

7. Amaya García M, Acosta Feria M, Soto Moreno A, et al. Primary hyperparathyroidism in pregnancy. Gynecol Endocrinol. 2004;19(2):111-114.

8. Cemeroglu AP, Bober E, Buyukgebiz A. Prolonged hypocalcemia in a 2 month-old boy unmasking maternal diagnosisof primary hyperparathyroidism. J Pediatr Endocrinol Metab. 2001;14(6):785-787. doi:
10.1515/JPEM.2001.14.6.785.

9. Reading CC, Charboneau JW, James EM, et al. High resolution parathyroid sonography. AJR Am J Roentgenol. 1982;139(3):539-546. doi:78.176.60.211.

10. Truong MT, Lalakea ML, Robbins P, Friduss M. Primary hyperparathyroidism in pregnancy: a case series and review. Laryngoscope. 2008;118(11):19661969. doi:10.1097/MLG.0b013e318180276f.

11. Mitchell DM, Jüppner H. Regulation of calcium homeostasis and bone metabolism in the fetus and neonate. Curr Opin Endocrinol Diabetes Obes. 2010;17(1):25-30. doi:10.1097/ MED.0b013e328334f041.

12. Horjus C, Groot I, Telting D, et al. Cinacalcet for hyperparathyroidism in pregnancy and puerperium. J Pediatr Endocrinol Metab. 2009;22(8):741-9.

13. Nussbaum SR. Pathophysiology and management of severe hypercalcemia. Endocrinol Metab Clin North Am. 1993;22(2):343-362.

14. Wolfe HJ. Calcitonin: perspectives in current concepts. J Endocrinol Invest. 1982;5(6):423-432.

15. Pothiwala $\mathrm{P}$, Levine $\mathrm{SN}$. Parathyroid surgery in pregnancy: review of the literature and localization by aspiration for parathyroid hormone levels. J Perinatol. 2009;29(12):779-784. doi:10.1038/jp.2009.84.

16. Carella MJ, Gossain VV. Hyperparathyroidism and pregnancy: case report and review. J Gen Inter Med. 1992;7(4):448-453.

17. Poomthavorn P, Ongphiphadhanakul B, Mahachoklertwattana P. Transient neonatal hypoparathyroidism in two siblings unmasking maternal normocalcemic hyperparathyroidism. Eur J Pediatr. 2008;167(4):431434. doi: 10.1007/s00431-007-0528-6.

18. Ip P. Neonatal convulsion revealing maternal hyperparathyroidism: an unusual case of late neonatal hypoparathyroidism. Arch Gynecol Obstet. 2003;268(3):227-229. doi: 10.1007/s00404-0020316-5.

Copyright (C) 2015 The Author(s); This is an open-access article distributed under the terms of the Creative Commons Attribution License (http://creativecommons.org/licenses/by/4.0), which permits unrestricted use, distribution, and reproduction in any medium, provided the original work is properly cited. 